\title{
Decomposition of Intumescent Coatings: Comparison between a Numerical Method and Experimental Results
}

\author{
L. M. R. Mesquita, P. A. G. Piloto, M. A. P. Vaz, T. M. G. Pinto \\ An investigation of two different intumescent coatings used in steel fire protection has been performed to evaluate their efficiency. A set of ex- \\ perimental tests is presented. They were conducted in a cone calorimeter, considering different thicknesses and heat fluxes. Among other \\ quantities, the steel temperature and the intumescence thickness variation were measured. A numerical model for the paint decomposition is \\ also presented. Based on the intumescence experimental value, the model is able to provide a reasonably good prediction of the steel tempera- \\ ture evolution.
}

Keywords: Fire protection, intumescent coatings, cone calorimeter, char formation, heat transfer, energy equation, thermal decomposition, porosity, arrhenius equation, activation energy.

\section{Introduction}

Passive fire protection materials insulate steel structures from the effects of the elevated temperatures that may be generated during a fire. They can be divided into two types, non-reactive, of which the most common types are boards and sprays, and reactive, of which intumescent coatings are an example. They are available as solvent- or water-based systems applied up to approximately $3 \mathrm{~mm}$. One problem associated with the use of such systems is the adhesion of the charred structure to the steel element during and after a fire. It is very important that the char remains in the steel surface to ensure fire protection.

Intumescent chemistry has changed little in recent years, and almost all coatings are largely based on the presence of similar key components. The chemical compounds of intumescent systems are classified into four categories: a carbonisation agent, a carbon rich polyhydric compound that influences the amount of char formed and the rate of char formation; an acid source, and a foaming agent, which during their degradation release non-flammable gases such as $\mathrm{CO}_{2}$ and $\mathrm{NH}_{3}[1]$.

Activated by fire or heat, a sequential chemical reaction between several chemical products takes place. At higher temperatures, between $(200-300){ }^{\circ} \mathrm{C}$, the acid reacts with the carboniferous agent. The formed gases will expand, beginning the intumescence in the form of a carbonaceous char.

Different models handle the intumescent behaviour with char-forming polymers as a heat and mass transfer problem. Other existing models provide a suitable description regarding the intumescence and char formation using kinetic studies of thermal degradation, accounting the complex sequence of chemical reactions, thermal and transport phenomenon [2-5].

Due to the thermal decomposition complexity of intumescent coating systems, the models presented so far are based on several assumptions, the most relevant being the consideration of one-dimensional heat transfer through material, temperature and space independent thermal properties and the assumption of a constant incident heat flux where the heat losses by radiation and convection are ignored [3]. Some authors also assume that the thermochemical processes of intumescence occur without energy release or energy absorption [6]. Results show that the insulation efficiency of the char depends on the cell structure, and the low thermal conductivity of intumescent chars results from the pockets of trapped gas within the porous char which act as a blowing agent to the solid material.

In a previous work considering the results obtained from coated steel plates tested in a cone calorimeter, the authors studied intumescence as a single homogeneous layer. The steel temperature variation was considered, and with the intumescence thickness time variation an inverse one-dimensional heat conduction problem (IHCP) was applied to determine the intumescence effective thermal conductivity and thermal resistance [7].

This work presents an experimental study to assess the performance of water-based intumescent paints used as a passive fire protection material. These tests were performed in a cone calorimeter, in steel plates coated with two different paints, three dry film thicknesses and considering two different radiant heat fluxes. During tests, among other quantities, the steel temperature, the intumescence mass loss and thickness variation were measured. A numerical model is also presented to study the intumescence behaviour. The paint thermal decomposition numerical model is based on the conservation equation of energy, mass and momentum.

\section{Experimental tests performed in the cone calorimeter}

To assess the performance of two commercial water-based intumescent paints, a set of experimental tests was performed in a cone calorimeter, see Fig. 1 and Fig. 2. The steel plates are $100 \mathrm{~mm}$ squared and 4,6 mm thick, coated on one side with different dry film thicknesses and tested in a cone calorimeter, as prescribed by the ISO5660 standard [8]. Temperatures are measured by means of four thermocouples, type k, welded to the plate on the heating side and on the opposite side, at two different positions. The samples were weighed before and af- 


\begin{tabular}{|c|c|c|c|c|c|c|c|c|c|c|c|}
\hline \multicolumn{3}{|c|}{$\begin{array}{c}\text { Specimens } \\
\text { identification }\end{array}$} & $\begin{array}{c}\text { Initial } \\
\text { Mass [g] }\end{array}$ & $\begin{array}{c}\text { Final } \\
\text { Mass [g] }\end{array}$ & $\begin{array}{c}\text { Coating } \\
\text { Mass [g] }\end{array}$ & $\begin{array}{c}\text { DFT } \\
{[? \mathbf{m}]}\end{array}$ & $\begin{array}{c}\mathbf{\sigma}(\mathbf{S D}) \\
{[? \mathbf{m}]}\end{array}$ & $\begin{array}{c}\text { Higher } \\
{[? \mathbf{m}]}\end{array}$ & $\begin{array}{c}\text { Smaller } \\
{[? \mathbf{m}]}\end{array}$ \\
\hline $\mathbf{A}$ & $\mathbf{3 5}$ & $\mathbf{4}$ & $\mathbf{0 . 5}$ & $\mathbf{1 - 3}$ & 363.77 & 371.28 & 7.51 & 545 & 40.6 & 601 & 478 \\
\hline $\mathbf{A}$ & $\mathbf{3 5}$ & $\mathbf{4}$ & $\mathbf{0 . 5}$ & $\mathbf{2 - 3}$ & 363.82 & 369.98 & 6.16 & 615 & 51.5 & 695 & 504 \\
\hline $\mathbf{A}$ & $\mathbf{3 5}$ & $\mathbf{4}$ & $\mathbf{0 . 5}$ & $\mathbf{3}$ & 364.54 & 373.19 & 8.65 & 528 & 60.4 & 624 & 427 \\
\hline
\end{tabular}

\begin{tabular}{|l|l|l|l|l|l|l|l|l|l|l|l|}
\hline $\mathbf{A}$ & $\mathbf{3 5}$ & $\mathbf{4}$ & $\mathbf{1 . 5}$ & $\mathbf{1}$ & 361.10 & 387.74 & 26.64 & 1670 & 107 & 1860 & 1500 \\
\hline $\mathbf{A}$ & $\mathbf{3 5}$ & $\mathbf{4}$ & $\mathbf{1 . 5}$ & $\mathbf{2}$ & 362.17 & 388.06 & 25.89 & 1610 & 72.2 & 1750 & 1500 \\
\hline $\mathbf{A}$ & $\mathbf{3 5}$ & $\mathbf{4}$ & $\mathbf{1 . 5}$ & $\mathbf{3}$ & 361.38 & 385.42 & 24.04 & 1450 & 84.9 & 1580 & 1280 \\
\hline
\end{tabular}

\begin{tabular}{|c|c|c|c|c|c|c|c|c|c|c|c|}
\hline $\mathbf{A}$ & $\mathbf{3 5}$ & $\mathbf{4}$ & $\mathbf{2 . 5}$ & $\mathbf{1 - 2}$ & 362.81 & 400.38 & 37.54 & 2530 & 165 & 2800 & 2240 \\
\hline $\mathbf{A}$ & $\mathbf{3 5}$ & $\mathbf{4}$ & $\mathbf{2 . 5}$ & $\mathbf{2}$ & 365.81 & 407.89 & 42.08 & 2590 & 122 & 2790 & 2310 \\
\hline $\mathbf{A}$ & 35 & $\mathbf{4}$ & $\mathbf{2 . 5}$ & $\mathbf{3 - 2}$ & 363.4 & 404.38 & 40.89 & 2680 & 179 & 2920 & 2370 \\
\hline
\end{tabular}
\begin{tabular}{|l|l|c|c|c|c|c|c|c|c|c|c|}
\hline $\mathbf{A}$ & $\mathbf{3 5}$ & $\mathbf{4}$ & $\mathbf{2 . 5}$ & $\mathbf{2}$ & 365.81 & 407.89 & 42.08 & 2590 & 122 & 2790 & 2310 \\
\hline $\mathbf{A}$ & $\mathbf{3 5}$ & $\mathbf{4}$ & $\mathbf{2 . 5}$ & $\mathbf{3 - 2}$ & 363.49 & 404.38 & 40.89 & 2680 & 179 & 2920 & 2370 \\
\hline
\end{tabular}

\begin{tabular}{|c|c|c|c|c|c|c|c|c|c|c|c|}
\hline $\mathbf{A}$ & $\mathbf{7 5}$ & $\mathbf{4}$ & $\mathbf{0 . 5}$ & $\mathbf{1}$ & 363.46 & 372.34 & 8.88 & 549 & 60.3 & 639 & 425 \\
\hline $\mathbf{A}$ & $\mathbf{7 5}$ & $\mathbf{4}$ & $\mathbf{0 . 5}$ & $\mathbf{2 - 2}$ & 363.58 & 371.33 & 7.75 & 586 & 36.3 & 651 & 538 \\
\hline $\mathbf{A}$ & $\mathbf{7 5}$ & $\mathbf{4}$ & $\mathbf{0 . 5}$ & $\mathbf{3}$ & 368.44 & 377.85 & 9.41 & 582 & 48.6 & 657 & 466 \\
\hline
\end{tabular}

\begin{tabular}{|l|l|l|l|l|l|l|l|l|l|l|l|}
\hline $\mathbf{A}$ & $\mathbf{7 5}$ & $\mathbf{4}$ & $\mathbf{1 . 5}$ & $\mathbf{1}$ & 369.59 & 394.82 & 25.23 & 1510 & 83.7 & 1660 & 1390 \\
\hline $\mathbf{A}$ & $\mathbf{7 5}$ & $\mathbf{4}$ & $\mathbf{1 . 5}$ & $\mathbf{2}$ & 371.11 & 396.24 & 25.13 & 1530 & 87.7 & 1720 & 1380 \\
\hline $\mathbf{A}$ & $\mathbf{7 5}$ & $\mathbf{4}$ & $\mathbf{1 . 5}$ & $\mathbf{3}$ & 364.87 & 391.13 & 26.26 & 1620 & 98.7 & 1820 & 1450 \\
\hline
\end{tabular}

\begin{tabular}{|c|c|c|c|c|c|c|c|c|c|c|c|}
\hline $\mathbf{A}$ & $\mathbf{7 5}$ & $\mathbf{4}$ & $\mathbf{2 . 5}$ & $\mathbf{1}$ & 366.97 & 407.71 & 40.74 & 2590 & 122 & 2760 & 2330 \\
\hline $\mathbf{A}$ & $\mathbf{7 5}$ & $\mathbf{4}$ & $\mathbf{2 . 5}$ & $\mathbf{2}$ & 365.11 & 404.90 & 39.79 & 2590 & 134 & 2800 & 2350 \\
\hline
\end{tabular}

\begin{tabular}{|l|l|l|l|l|l|l|l|l|l|l|l|}
\hline $\mathbf{A}$ & $\mathbf{7 5}$ & $\mathbf{4}$ & $\mathbf{2 . 5}$ & $\mathbf{1}$ & 366.97 & 407.71 & 40.74 & 2590 & 122 & 2760 & 2330 \\
\hline $\mathbf{A}$ & $\mathbf{7 5}$ & $\mathbf{4}$ & $\mathbf{2 . 5}$ & $\mathbf{2}$ & 365.11 & 404.90 & 39.79 & 2590 & 134 & 2800 & 2350 \\
\hline $\mathbf{A}$ & $\mathbf{7 5}$ & $\mathbf{4}$ & $\mathbf{2 . 5}$ & $\mathbf{3}$ & 370.60 & 410.77 & 40.17 & 2530 & 167 & 2810 & 2260 \\
\hline
\end{tabular}

\begin{tabular}{|c|c|c|c|c|c|c|c|c|c|c|c|}
\hline $\mathbf{A}$ & $\mathbf{3 5}$ & $\mathbf{6}$ & $\mathbf{0 . 5}$ & $\mathbf{1}$ & 527.37 & 535.05 & 7.68 & 476 & 33.1 & 518 & 403 \\
\hline $\mathbf{A}$ & $\mathbf{3 5}$ & $\mathbf{6}$ & $\mathbf{2 . 5}$ & $\mathbf{1}$ & 526.65 & 565.71 & 39.06 & 2420 & 150 & 2610 & 2130 \\
\hline $\mathbf{A}$ & $\mathbf{7 5}$ & $\mathbf{6}$ & $\mathbf{0 . 5}$ & $\mathbf{1}$ & 522.90 & 530.58 & 7.68 & 494 & 33.9 & 561 & 434 \\
\hline $\mathbf{A}$ & $\mathbf{7 5}$ & $\mathbf{6}$ & $\mathbf{2 . 5}$ & $\mathbf{1}$ & 525.71 & 564.89 & 39.18 & 2490 & 112 & 2670 & 2290 \\
\hline
\end{tabular}

\begin{tabular}{|c|c|c|c|c|c|c|c|c|c|c|c|}
\hline \multicolumn{4}{|c|}{$\begin{array}{c}\text { Specimens } \\
\text { identification }\end{array}$} & $\begin{array}{c}\text { Initial } \\
\text { Mass [g] }\end{array}$ & $\begin{array}{c}\text { Final } \\
\text { Mass [g] }\end{array}$ & $\begin{array}{c}\text { Coating } \\
\text { Mass [g] }\end{array}$ & $\begin{array}{c}\text { DFT } \\
{[? \mathbf{m}]}\end{array}$ & $\begin{array}{c}\boldsymbol{\sigma} \text { (SD) } \\
{[? \mathbf{m}]}\end{array}$ & $\begin{array}{c}\text { Higher } \\
{[? \mathbf{m}]}\end{array}$ & $\begin{array}{c}\text { Smaller } \\
{[? \mathbf{m}]}\end{array}$ \\
\hline $\mathbf{B}$ & $\mathbf{3 5}$ & $\mathbf{4}$ & $\mathbf{0 . 5}$ & $\mathbf{1}$ & 366.73 & 375.36 & 8.63 & 571 & 41.6 & 665 & 506 \\
\hline $\mathbf{B}$ & $\mathbf{3 5}$ & $\mathbf{4}$ & $\mathbf{0 . 5}$ & $\mathbf{2}$ & 365.38 & 374.88 & 9.50 & 626 & 38.6 & 698 & 563 \\
\hline $\mathbf{B}$ & $\mathbf{3 5}$ & $\mathbf{4}$ & $\mathbf{0 . 5}$ & $\mathbf{3}$ & 364.95 & 373.95 & 9.00 & 603 & 49.5 & 710 & 481 \\
\hline
\end{tabular}

\begin{tabular}{|l|l|l|l|l|l|l|l|l|l|l|l|}
\hline B & $\mathbf{3 5}$ & $\mathbf{4}$ & $\mathbf{1 . 5}$ & $\mathbf{1}$ & 365.63 & 390.10 & 24.47 & 1510 & 70.2 & 1610 & 1400 \\
\hline B & $\mathbf{3 5}$ & $\mathbf{4}$ & $\mathbf{1 . 5}$ & $\mathbf{2}$ & 365.82 & 391.42 & 25.60 & 1570 & 64.1 & 1670 & 1470 \\
\hline B & $\mathbf{3 5}$ & $\mathbf{4}$ & $\mathbf{1 . 5}$ & $\mathbf{3}$ & 364.80 & 390.67 & 25.87 & 1580 & 66.5 & 1710 & 1470 \\
\hline
\end{tabular}

\begin{tabular}{|l|l|l|l|l|l|l|l|l|l|l|l|}
\hline B & $\mathbf{3 5}$ & $\mathbf{4}$ & $\mathbf{2 . 5}$ & $\mathbf{1}$ & 365.49 & 409.85 & 44.36 & 2640 & 90.9 & 2750 & 2460 \\
\hline B & $\mathbf{3 5}$ & $\mathbf{4}$ & $\mathbf{2 . 5}$ & $\mathbf{2}$ & 366.29 & 409.12 & 42.83 & 2560 & 89.0 & 2660 & 2400 \\
\hline
\end{tabular}

\begin{tabular}{|l|l|l|l|l|l|l|l|l|l|l|l|l|}
\hline $\mathbf{B}$ & $\mathbf{3 5}$ & $\mathbf{4}$ & $\mathbf{2 . 5}$ & $\mathbf{2}$ & 366.29 & 409.12 & 42.83 & 2560 & 89.0 & 2660 & 2400 \\
\hline $\mathbf{B}$ & $\mathbf{3 5}$ & $\mathbf{4}$ & $\mathbf{2 . 5}$ & $\mathbf{3}$ & 366.40 & 407.77 & 41.37 & 2510 & 85.7 & 2660 & 2350 \\
\hline
\end{tabular}

\begin{tabular}{|c|c|c|c|c|c|c|c|c|c|c|c|}
\hline B & $\mathbf{7 5}$ & $\mathbf{4}$ & $\mathbf{0 . 5}$ & $\mathbf{1}$ & 362.92 & 371.94 & 9.02 & 581 & 35.9 & 653 & 518 \\
\hline B & $\mathbf{7 5}$ & $\mathbf{4}$ & $\mathbf{0 . 5}$ & $\mathbf{2}$ & 366.00 & 375.97 & 9.97 & 662 & 53.9 & 817 & 599 \\
\hline B & $\mathbf{7 5}$ & $\mathbf{4}$ & $\mathbf{0 . 5}$ & $\mathbf{3}$ & 367.53 & 377.53 & 10.00 & 631 & 31.2 & 707 & 583 \\
\hline
\end{tabular}

\begin{tabular}{|l|l|l|l|l|l|l|l|l|l|l|l|}
\hline B & $\mathbf{7 5}$ & $\mathbf{4}$ & $\mathbf{1 . 5}$ & $\mathbf{1}$ & 366.27 & 390.71 & 24.44 & 1530 & 79.5 & 1720 & 1440 \\
\hline B & $\mathbf{7 5}$ & $\mathbf{4}$ & $\mathbf{1 . 5}$ & $\mathbf{2}$ & 364.69 & 389.63 & 24.94 & 1550 & 67.8 & 1690 & 1450 \\
\hline B & $\mathbf{7 5}$ & $\mathbf{4}$ & $\mathbf{1 . 5}$ & $\mathbf{3}$ & 359.09 & 384.05 & 24.96 & 1560 & 74.9 & 1740 & 1450 \\
\hline
\end{tabular}

\begin{tabular}{|l|l|l|l|l|l|l|l|l|l|l|l|}
\hline B & $\mathbf{7 5}$ & $\mathbf{4}$ & $\mathbf{2 . 5}$ & $\mathbf{1}$ & 359.79 & 399.66 & 39.87 & 2520 & 211 & 2840 & 2170 \\
\hline B & $\mathbf{7 5}$ & $\mathbf{4}$ & $\mathbf{2 . 5}$ & $\mathbf{2}$ & 364.28 & 405.30 & 41.02 & 2520 & 91.4 & 2690 & 2350 \\
\hline
\end{tabular}

\begin{tabular}{|l|l|l|l|l|l|l|l|l|l|l|l|}
\hline B & $\mathbf{7 5}$ & $\mathbf{4}$ & $\mathbf{2 . 5}$ & $\mathbf{2}$ & 364.28 & 405.30 & 41.02 & 2520 & 91.4 & 2690 & 2350 \\
\hline B & $\mathbf{7 5}$ & $\mathbf{4}$ & $\mathbf{2 . 5}$ & $\mathbf{3}$ & 364.80 & 404.97 & 40.17 & 2490 & 126 & 2760 & 2340 \\
\hline
\end{tabular}

\begin{tabular}{|c|c|c|c|c|c|c|c|c|c|c|c|}
\hline B & $\mathbf{3 5}$ & $\mathbf{6}$ & $\mathbf{0 . 5}$ & $\mathbf{1}$ & 528.60 & 537.10 & 8.50 & 533 & 56.7 & 663 & 431 \\
\hline B & $\mathbf{3 5}$ & $\mathbf{6}$ & $\mathbf{2 . 5}$ & $\mathbf{1}$ & 528.91 & 571.74 & 42.83 & 2570 & 105 & 2720 & 2360 \\
\hline B & $\mathbf{7 5}$ & $\mathbf{6}$ & $\mathbf{0 . 5}$ & $\mathbf{1}$ & 525.47 & 534.86 & 9.39 & 607 & 65.9 & 799 & 528 \\
\hline B & $\mathbf{7 5}$ & $\mathbf{6}$ & $\mathbf{2 . 5}$ & $\mathbf{1}$ & 529.04 & 570.00 & 40.96 & 2610 & 75.8 & 2760 & 2500 \\
\hline
\end{tabular}

Fig. 1: Set of experimental tests. Reference: Paint/Heat Flux/Steel Thick./Dry Thick/Test $N^{\circ}$

ter being coated, to allow for the initial coating mass. The dry thickness was also measured in 16 different points. The mean values and the standard deviation are presented in Fig. 1.

Between the steel plate and the sample older, two silicate plates were used to put the specimen in place and also a thermocouple was placed to measure its temperature variation. The distance between the sample surface and the heater remained unchanged, at approximately $60[\mathrm{~mm}]$. This means
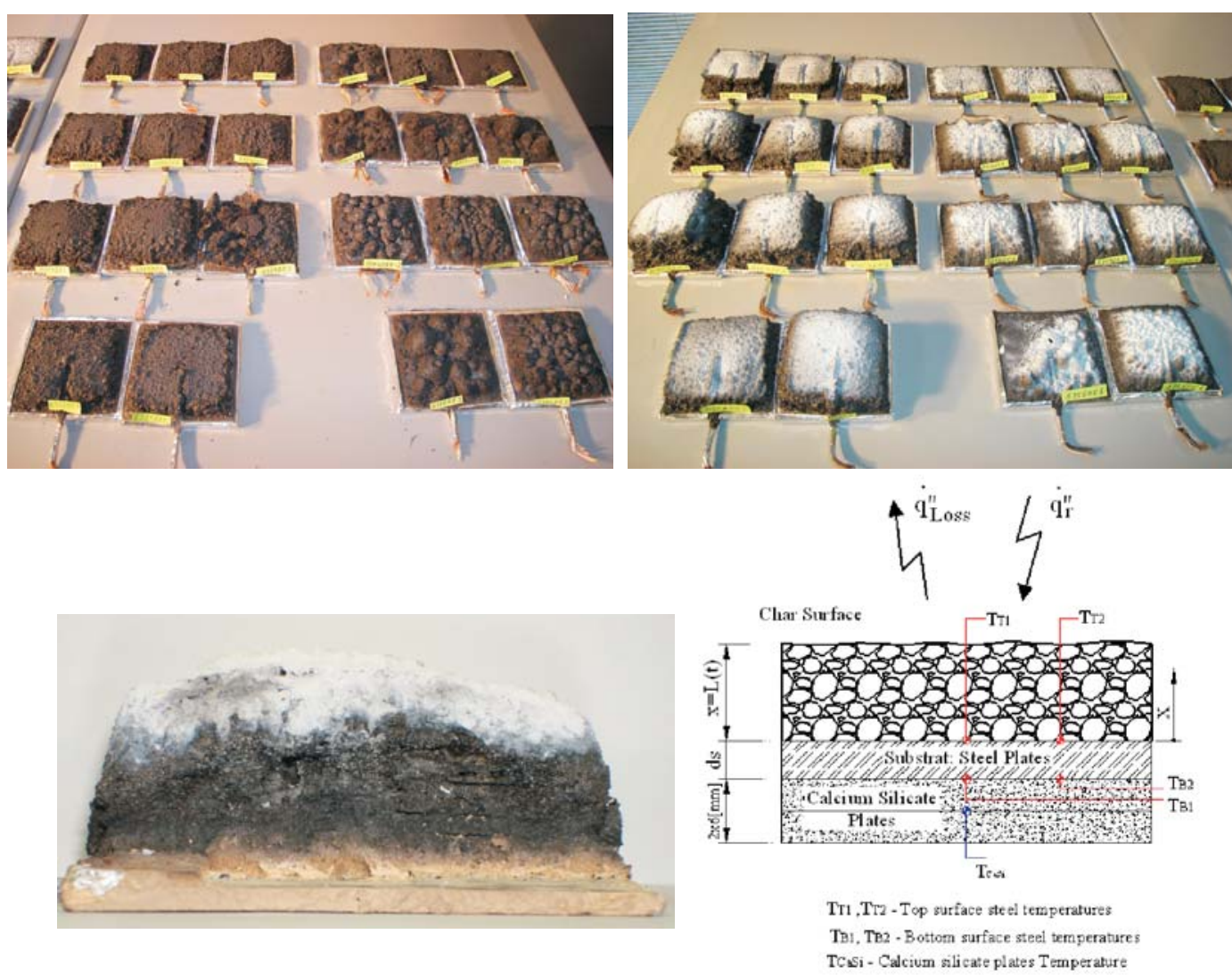

Fig. 2: Coated steel plates, with fixed thermocouples. Tested samples at $35 \mathrm{~kW} / \mathrm{m}^{2}$ and at $75 \mathrm{~kW} / \mathrm{m}^{2}$, reference and position of the thermocouples.

(C) Czech Technical University Publishing House http://ctn.cvut.cz/ap/ 


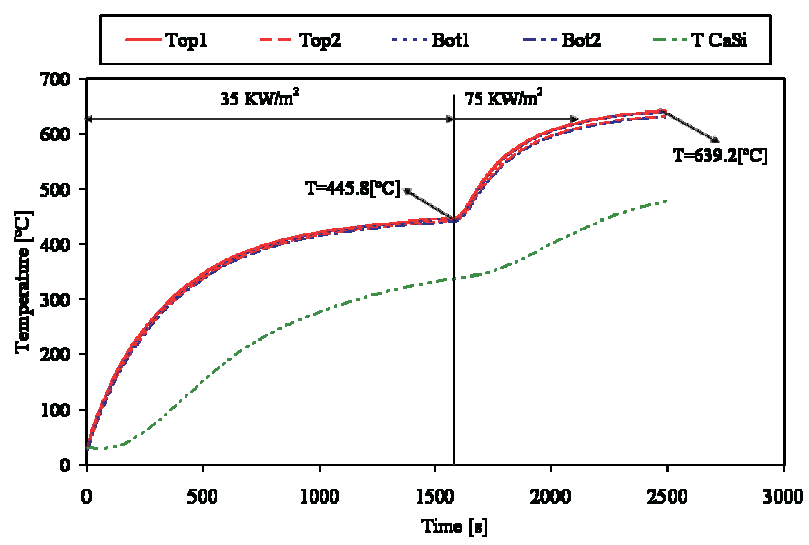

Fig. 3: Measured temperature in the steel plate without protection

Fig. 3 for a radiant heat flux of $35 \mathrm{KW} / \mathrm{m}^{2}$ and then resetting the cone to $75 \mathrm{KW} / \mathrm{m}^{2}$.

Fig. 4 represents the mass loss of each sample and shows a variation almost linear with time, mainly for a heat flux of $35 \mathrm{~kW} / \mathrm{m}^{2}$.

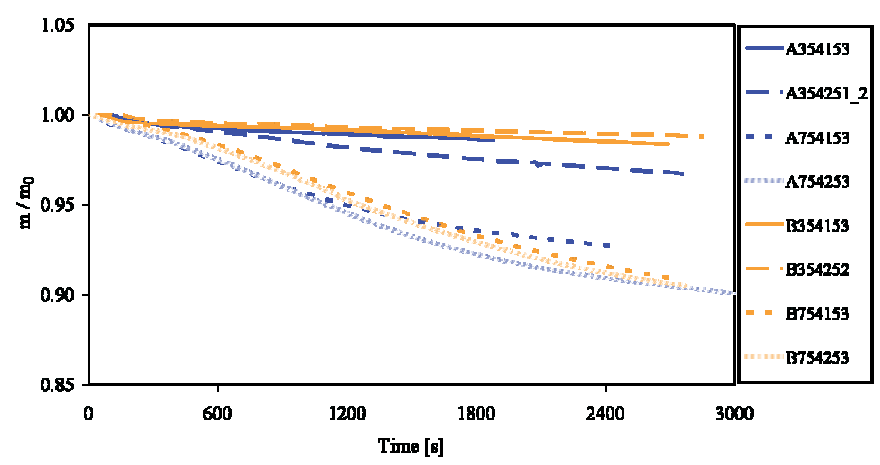

Fig. 4: Measured mass loss with time
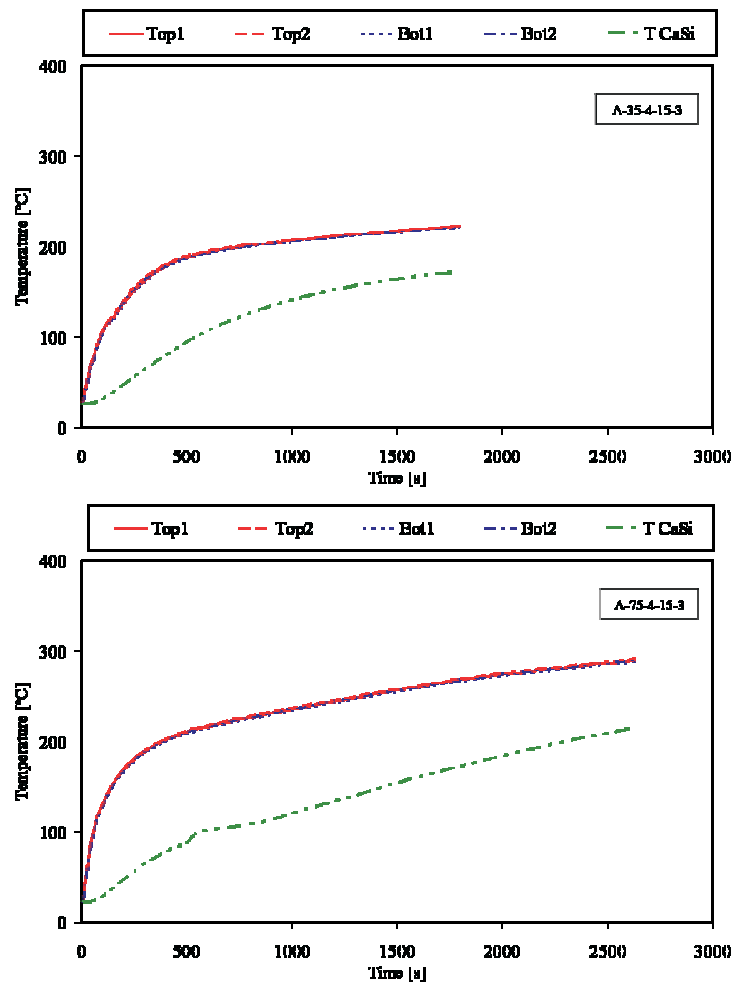

Fig. 6: Temperature variation of steel and silicate plates for coating A
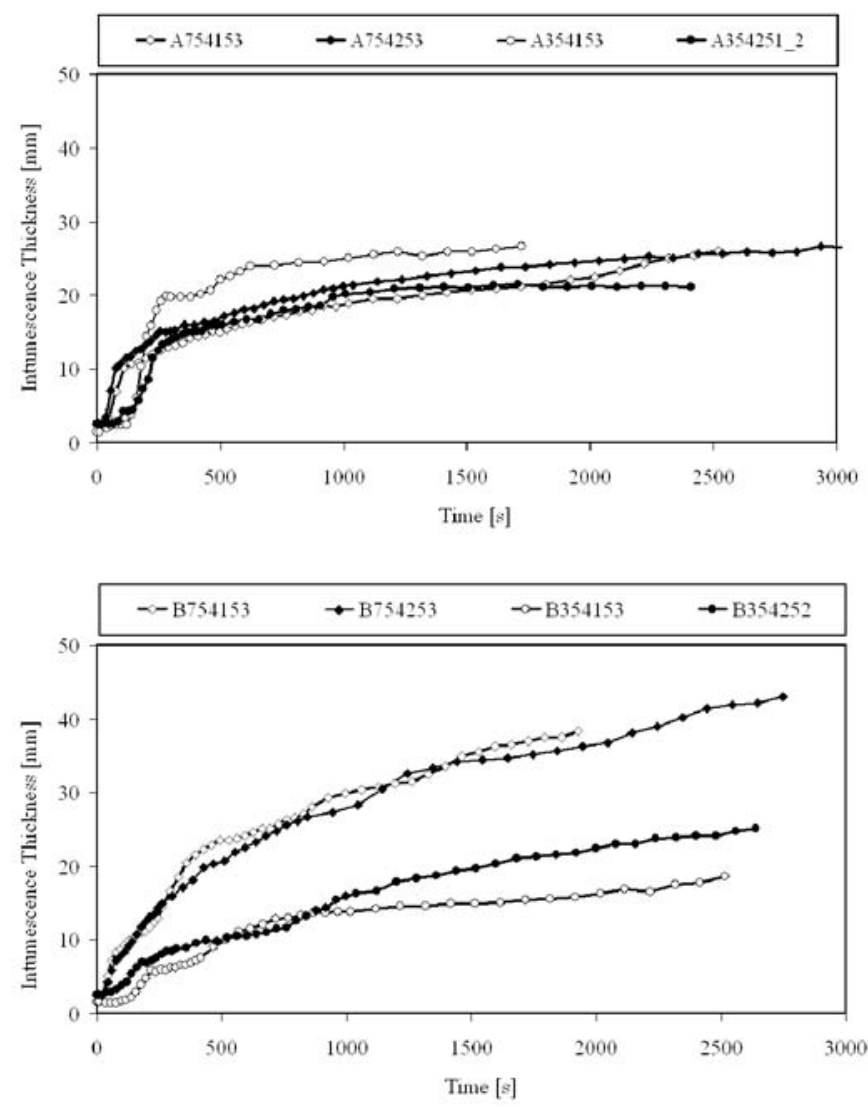

Fig. 5: Intumescence thickness mean values of four central measurements

Using discrete frames obtained from a digital camera during the tests, and by image processing techniques using Matlab, the intumescence development was measured over time. Fig. 5 presents the intumescent development (free
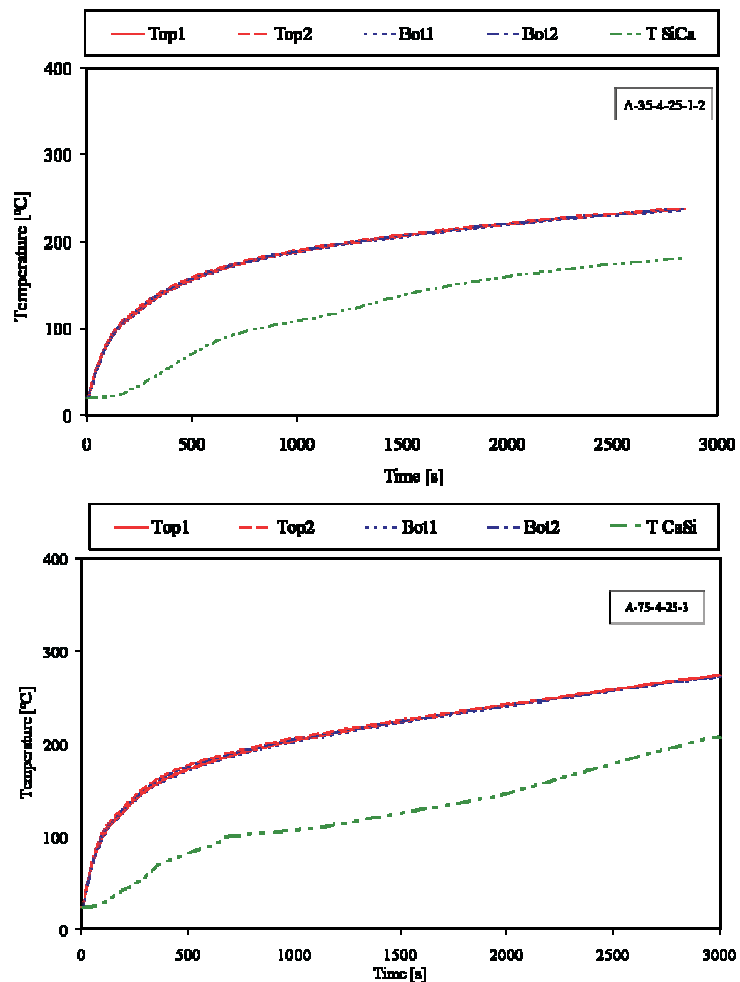

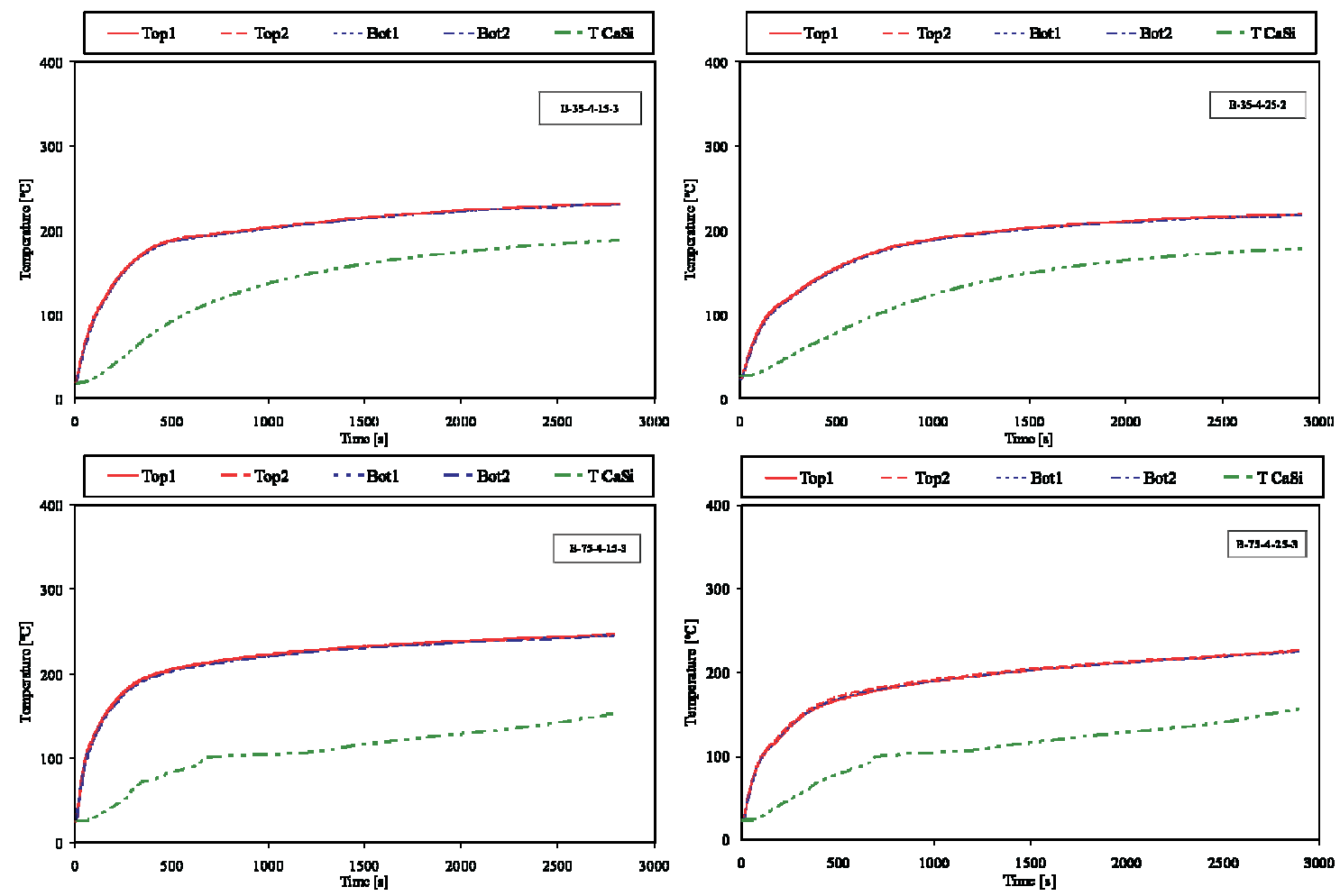

Fig. 7: Temperature variation of steel and silicate plates for coating B

boundary $L(t))$ for specimens with paint A and B, different thicknesses and radiant heat fluxes.

Higher intumescence may be observed in the sample right region coincident to the thermocouple wire position responsible for coating accumulation. The presented values are mean values determined from four central measures.

The figures show that for the lower heat flux the intumescence becomes stable, but for the higher heat flux it continues to increase. Coating A presents a higher expansion at the initial stage compared to coating B. For longer periods of exposure coating B continues to expand.

The steel temperature profiles and temperatures in the middle of the silicate plates are reported in Fig. 6 and Fig. 7 . Measured values from the thermocouples welded to the bottom of the plate are very close to the temperatures at the top. For the same heat flux, the time to reach the same temperature increases with the increase of the dry thickness.

The behaviour is very similar for both coatings, but for all cases the time to reach, e.g., a temperature of $200{ }^{\circ} \mathrm{C}$ is always higher when paint B is used. For these conditions it gives improved fire protection.

\section{Mathematical model of the intumescence behaviour}

To determine the temperature field in an intumescent material, it is necessary to solve a phase transformation problem with two ore more moving boundaries that characterize its state, initial, softened and carbonaceous char. Different methodologies can be found in the literature to model the thermal decomposition of a polymer or polymer based materials. The methodology followed in this work was to consider that the decomposition occurs not only at the outside surface but also inside, for temperatures above the pyrolysis temperature, $T_{\mathrm{p}}$. In this case the moving boundary regression rate must be determined considering the motion of the whole domain. This strategy implies that a mass diffusion term needs to appear in the energy equation due to its motion. This term was disregarded due to the small thickness of the virgin layer for this types of applications, about $1-3 \mathrm{~mm}$.

Considering a first order reaction, the mass loss is given by

$\dot{m}(T(x, t))=\frac{\partial \rho_{\mathrm{v}}}{\partial t}=-\rho_{\mathrm{v}} A_{0} e^{-\frac{E_{0}}{R T(x, T)}}$ for $T \geq T_{p}$,

where $\dot{m}$ is the local mass loss $\mathrm{kg} \cdot \mathrm{m}^{-3} \cdot \mathrm{s}^{-1}, T(x, t)$ is the temperature at point $x$ at instant $t, A_{0}$ is the pre exponential factor $\left[\mathrm{s}^{-1}\right], E_{0}$ the activation energy $\left[\mathrm{J} \cdot \mathrm{mol}^{-1}\right]$, and $R$ the universal gas constant $\left[\mathrm{J} \cdot \mathrm{mol}^{-1} \cdot \mathrm{K}^{-1}\right]$. The position of the moving boundary is obtained by summing all the mass loss and dividing by the specific mass.

The energy equation for the steel and virgin layers is based on the one-dimensional conduction heat equation.

The conservation equation for the solid virgin material phase is given by

$$
\frac{\partial \rho_{\mathrm{v}} V_{\mathrm{v}}}{\partial t}=-\dot{w}_{\mathrm{v}}^{m_{d}} V_{\mathrm{v}}
$$

where $\dot{\omega}_{\mathrm{v}}^{m_{d}}$ represents the destruction rate of virgin material per unit volume, originated by the thermal decomposition. The virgin material decomposition produces a fraction of gas, equal to the porosity, $\varphi$, and a solid char fraction equal to $(1-\varphi)$. 
The formation rate of char and gas mass is:

$$
\begin{aligned}
& \dot{w}_{\text {gas }}^{p}=-\left(1-\frac{\rho_{\mathrm{C}}}{\rho_{\mathrm{v}}}\right) \chi \rho_{\mathrm{v}} A \frac{\mathrm{d} s(t)}{\mathrm{d} t}, \\
& \dot{w}_{\text {char }}^{p}=-\left[1-\left(1-\frac{\rho_{\mathrm{c}}}{\rho_{\mathrm{v}}}\right) \chi\right] \rho_{\mathrm{v}} A \frac{\mathrm{d} s(t)}{\mathrm{d} t} .
\end{aligned}
$$

$\chi$ represents the fraction of the bulk density difference between the virgin and char materials that is converted to gas. In this study the value used was $\chi=0.66$, [9].

The conservation of gas mass equation is given by Eq. (4).

$$
\frac{\partial\left(\rho_{\mathrm{g}} \varphi\right)}{\partial t}+\frac{\rho_{\mathrm{g}} \varphi}{V} \frac{\partial V}{\partial t}+\frac{\partial \dot{m}_{\mathrm{g}}^{\prime \prime}}{\partial x}=0 .
$$

In the previous equation, $\partial V / \partial t$ represents the intumescence rate. The gas mass flux, $\dot{m}_{\mathrm{g}}^{\prime \prime}$, is calculated accordingly to Darcy's law and it is assumed that the gases present in the intumescent material behave as a perfect gas. The thermodynamic properties are related by the ideal gas law and, assuming that the gas is a mixture of $50 w t \% \mathrm{CO}_{2}$ and $50 w t \% \mathrm{H}_{2} \mathrm{O}$, the generated gas molar mass used in the model $M_{\mathrm{g}}$ is $31 \mathrm{~g} / \mathrm{mol}$.

The conservation of gas mass equation with the Darcy and the ideal gas laws combined can be used to give a differential equation for the pressure inside the intumescence. In the numeric calculations, the intumescence rate is assumed to be known, provided by experimental results, so the pressure calculation is disregarded on the assumption that the internal pressure is constant and equal to the atmospheric pressure. An energy equation for the conservation of energy within the intumescence zone can be obtained by combining the energy equation for the gases with that of the solid char material. The equation for the conservation of energy per unit bulk volume can be written as:

$$
\begin{aligned}
(\rho C p)_{\mathrm{eff}} \frac{\partial T}{\partial t}+\frac{\partial}{\partial x}\left(\dot{m}_{\mathrm{g}}^{\prime \prime} T_{\mathrm{g}} C p_{\mathrm{g}}\right) & =\frac{\partial}{\partial x}\left(k_{\mathrm{eff}} \frac{\partial T}{\partial x}\right)-C p T \frac{\partial \rho}{\partial t} \\
& -(\rho C p)_{\mathrm{eff}} \frac{T}{V} \frac{\partial V}{\partial t}
\end{aligned}
$$

where

and

$$
(\rho C p)_{\mathrm{eff}}=\varphi \rho_{\mathrm{g}} C p_{\mathrm{g}}+(1-\varphi) \rho_{\mathrm{c}} C p_{\mathrm{c}}
$$

$$
k_{\mathrm{eff}}=\varphi k_{\mathrm{g}}+(1-\varphi) k_{\mathrm{c}}
$$

The effective thermal conductivity for the intumescence bulk material, including gas and char, is equal to the thermal conductivity of the gas per unit bulk volume, plus that of the solid material. The same thing applies to the effective heat capacity.

In the steel plate back surface we assume an adiabatic boundary condition, and at the boundary steel/virgin layers we assume a perfect thermal contact. At the moving front, the boundary conditions are:

$$
\begin{array}{ll}
k_{\mathrm{v}} \frac{\partial T}{\partial x}=\varepsilon \dot{q}_{r}^{\prime \prime}-\varepsilon \sigma\left(T^{4}-T_{a}^{4}\right)-h_{\mathrm{c}}\left(T-T_{a}\right) & \text { for } T(s(t), t)<T_{\mathrm{p}}, \\
k_{\mathrm{v}} \frac{\partial T}{\partial x}-k_{\mathrm{c}} \frac{\partial T}{\partial x}-=Q_{H} & \text { for } T(s(t), t)=T_{\mathrm{p}},
\end{array}
$$

in which $Q_{H}$ is the heat flux due to the endothermic decomposition of the virgin material, given by $Q_{H}=-h_{\mathrm{p}} \rho_{\mathrm{v}} \dot{s}(t)$, where $h_{\mathrm{p}}$ represents the decomposition enthalpy. A wide range of values are reported in the literature for the heat of pyrolysis, ranging from a few units to units of millions. The value used in the calculations was $50 \mathrm{~J} / \mathrm{kg}$.

The intumescent coating specific mass was measured by the pycnometer method given a value of 1360 and $1250 \mathrm{~kg} / \mathrm{m}^{3}$ for the virgin coating and a value of 692.4 and $450 \mathrm{~kg} / \mathrm{m}^{3}$ for the char material, for paints A and B, respectively. The steel properties are assumed constant, with a specific heat value of $600 \mathrm{~J} / \mathrm{kg} \cdot \mathrm{K}$ and a specific mass equal to $7850 \mathrm{~kg} / \mathrm{m}^{3}$.

The mathematical model is based on the following major simplifying assumptions: there is no heat between gas and char, the thermophysical properties and the pressure at both layers are constant.

The solution method was implemented in a Matlab routine using the Method Of Lines (MOL), [10], and the integrator ode15s to solve the set of ordinary differential equations.

The temperature field is determined by the steel and virgin energy equations. When the front reaches the pyrolysis temperature, equal to $250{ }^{\circ} \mathrm{C}$, it starts to decompose and to move. Then the moving front rate is determined and the intumescence forms. The position the free boundary is set equal to the experimental results and the intumescence temperature field is determined. In each time step the virgin and char layers are remeshed.

The input parameters are listed as follows:

$$
\begin{aligned}
& k_{\mathrm{v}}=0.5 \mathrm{~W} \cdot \mathrm{m}^{-1} \cdot \mathrm{K}^{-1} ; k_{\mathrm{c}}=0.1 \mathrm{~W} \cdot \mathrm{m}^{-1} \cdot \mathrm{K}^{-1} ; \\
& C p_{\mathrm{v}}=2600 \mathrm{~J} \cdot \mathrm{kg}^{-1} \cdot \mathrm{K}^{-1} ; C p_{\mathrm{c}}=3000 \mathrm{~J} \cdot \mathrm{kg}^{-1} \cdot \mathrm{K}^{-1} ; \\
& h_{\mathrm{c}}=20 \mathrm{~W} \cdot \mathrm{m}^{2} \cdot \mathrm{K}^{-1} ; \varepsilon=0.92 ; \\
& T_{\mathrm{p}}=525 \mathrm{~K} ; A_{0}=4.67 \mathrm{e}^{12} \cdot \mathrm{s}^{-1} .
\end{aligned}
$$

Two case studies are presented in Fig. 8 and Fig. 9. In the first study, the steel temperature variation and the moving front position are determined based on a value of the acti-
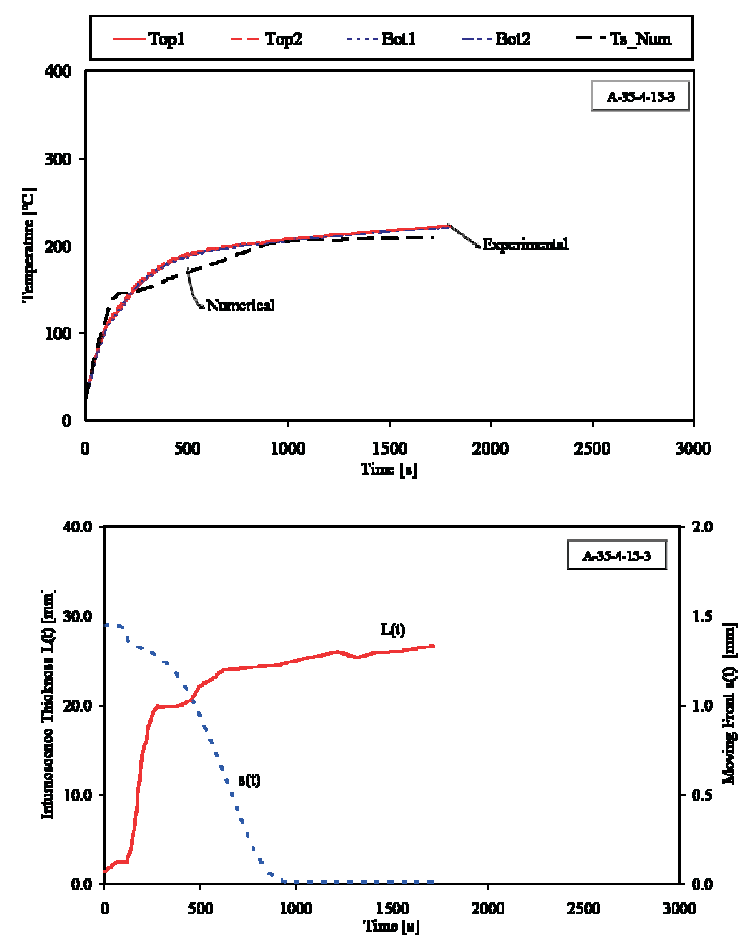

Fig. 8: Comparison of measured and computed steel temperatures and position of the moving front, $E_{0}=125 \mathrm{~K} \cdot \mathrm{J} \cdot \mathrm{mol}^{-1}$ 

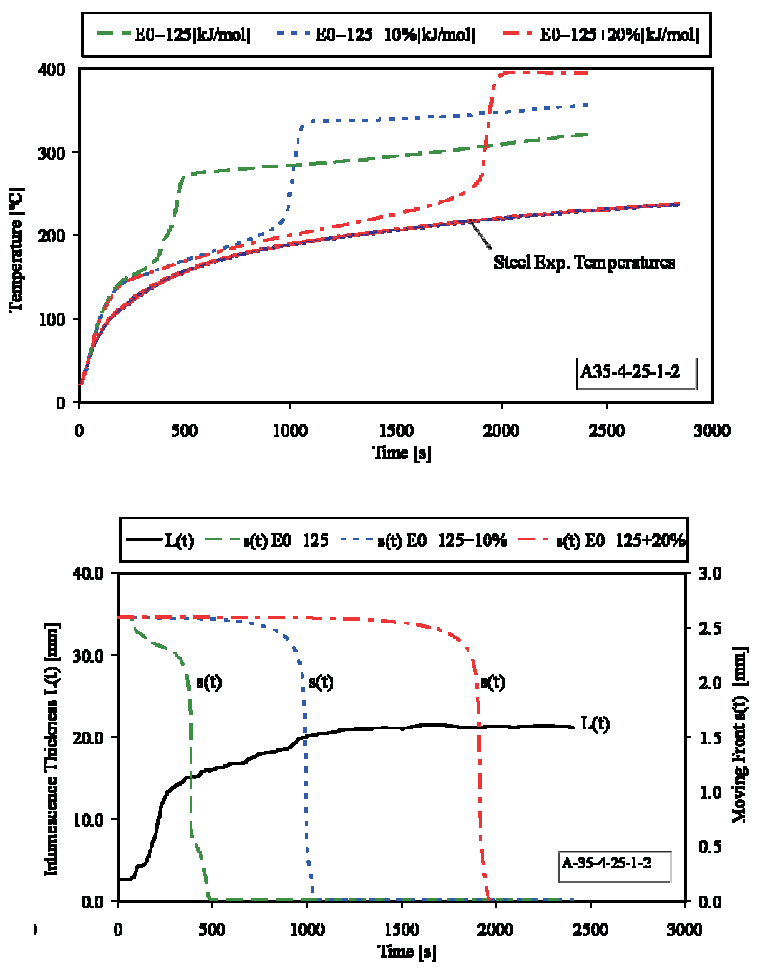

Fig. 9: Influence of the activation energy in the steel temperature and in the moving front

vation energy equal to $E_{0}=125 \mathrm{~K} \cdot \mathrm{J} \cdot \mathrm{mol}^{-1}$. The numerical results follow the experimental values reasonably well. The major differences occur at intermediate times, probably because a transition state of molten polymer was not considered.

Both the determined steel temperatures and the moving front are strongly dependent on the activation energy that defines the amount of mass loss of virgin paint, as presented in Fig. 9. It must be said that the value used in the simulations was obtained from the literature, but the correct values of both paints are needed. The reaction kinetics parameters can be obtained from thermogravimetric analysis.

\section{Acknowledgments}

The authors acknowledge financial support from the Portuguese Science and Technology Foundation, project PTDC/EME-PME/64913/2006, "Assessment of Intumescent Paint Behaviour for Passive Protection of Structural Elements Submitted to Fire Conditions", and fellowship SFRH/BD/ 28909/2006. The authors also acknowledge the contribution from the paints producers: CIN, Nullifire.

\section{References}

[1] Duquesne, S., Bourbigot, S., Delobel, R.: "Mechanism of Fire Protection in Intumescent Coatings". European
Coatings Conference: Fire Retardant Coatings II, Berlin, 2007.

[2] Staggs, J. E. J.: "A Discussion of Modelling Idealised Ablative Materials with Particular Reference to Fire Testing”, Fire Safety Journal, Vol. 28 (1997), p. 47-66.

[3] Moghtaderi, B., Novozhilov, V., Fletcher, D., Kent, J. H.: "An Integral Model for the Transient Pyrolysis of Solid Materials”. Fire and Materials, Vol. 21 (1997), p. 7-16.

[4] Lyon, R. E.: "Pyrolysis Kinetics of Char Forming Polymers". Polymer Degradation and Stability, N1, Vol. 61 (1998), p. 201-210.

[5] Jia, F., Galea, E. R., Patel, M. K.: "Numerical Simulation of the Mass Loss Process in Pyrolizing Char Materials". Fire And Materials, N1, Vol. 23 (1999), p. 71-78.

[6] Kuznetsov, G. V., Rudzinskii, V. P.: "Heat Transfer in Intumescent Heat- and Fire-Insulating Coatings", Journal of Applied Mechanics and Technical Physics, Vol. 40 (1999), No. 3.

[7] Mesquita, L. M. R., Piloto, P. A. G., Vaz, M. A. P., Pinto, T.: "Numerical Estimation For Intumescent Thermal Protection Using One-Dimensional IHCP". WCCM8-ECCOMAS 2008, Venice, Italy, June 30-July 5, 2008. ISBN 978-84-96736-55-9.

[8] ISO 5660-1:2002: Reaction-To-Fire Tests - Heat Release, Smoke Production and Mass Loss Rate. Part 1: Heat Release Rate (cone calorimeter method), International Organization for Standardization, 2002.

[9] Lautenberger, C.: A Generalized Pyrolysis Model for Combustible Solids, Ph.D. thesis, University of California at Berkeley, Berkeley, CA, 2007.

[10] Wouwer, A. V, Saucez, P., Schiesser, W. E.: "Simulation of Distributed Parameter Systems Using a Matlab-Based Method of Lines Toolbox: Chemical Engineering Applications", Ind. Eng. Chem. Res. Vol. 43 (2004), p. 3469-3477.

Luís M. R. Mesquita

e-mail: lmesquita@ipb.pt

Paulo A. G. Piloto

Tiago M. G. Pinto

Applied Mechanics Department

Polytechnic Institute of Bragança

Portugal

Mário A. P. Vaz

Faculty of Engineering

University of Porto

Portugal 